\title{
Novel cyclic voltammetry behavior of 3-((benzothiazol-2- diazenylnaphthalene-2,7-diol and use it for spectrophotometric determination of copper (II )in honey sample
}

\author{
Fatma .A. Khazaal ${ }^{a}{ }^{*}{ }^{*}$ Hussein. J.Mohammed ${ }^{\mathrm{b}}$ and \\ .Muhammed .M.Radhi ${ }^{\mathrm{C}}$ \\ ${ }^{*}$ Chemistry Department / Faculty of Science /Kufa University, Iraq P.O Box(21) \\ Email Hussein.alshujairi@uokufa.edu.iq
}

\section{Abstract ;}

The azo reagent 3-((benzothiazol-2-diazenylnaphthalene-2,7-diol] was synthesized and characterized by FT-IR , ${ }^{1} \mathrm{H}-\mathrm{NMR}$ and ${ }^{13} \mathrm{CNMR}$ spectral techniques. The electrochemical behavior of the azo reagent and its complex with $\mathrm{Cu}$ (II) has been studied at glassy carbon disk GCE electrode in different supporting electrolyte at concentration (1M) and scan rate $\left(100 \mathrm{mv} \cdot \mathrm{s}^{-1}\right)$. Spectrophotometric determination of copper (II) is based on the formation of a $2: 1$ complex with above reagent. The complex has $\lambda \max$ at $(588) \mathrm{nm}$ and $\varepsilon \max$ of $\left(1.436 \times 10^{4}\right) \mathrm{L}_{\mathrm{mol}}{ }^{-1} . \mathrm{cm}^{-1}$.

A linear correlation $\left(0.1-3.0 \mu \mathrm{g} . \mathrm{ml}^{-1}\right)$ was found between absorbance at $\lambda$ max and concentration . The effect of diverse ions on the determination of copper (II) to investigate the selectivity of the method were also studied. The stability constant of the product was $\left(1.1 \times 10^{8}\right)$. The proposed method was successfully applied to the analysis of honey sample .

\section{m Key Words: Cyclic voltammetry,3(benzothiazol-2-diazenylnaphthalen- \\ 2,7diol],copper (II), spectroscopy.}

\section{Introduction :}

Azo compounds have been the most extensively used class of dyes owing to their versatile application in several fields, such as advanced application in organic synthesis, dyeing cloth fiber biomedical studies, azo dyes are also used in coloring agents in Pharmaceuticals and foods. Azo dyes have wide interest of applications in complexometric titration and in analytical chemistry. These compounds are also used in oils, plastics, waxes and polishes . In addition , azo compounds and their bio conjugates have attracted clinical interest related to photo therapy and photo diagnosis of tumors and their lesions [1-5]. The determination of metal ion at trace amount have been shown important in the fields of biological and environment studies literature date indication that azo compound have been broadly used in the spectrophtometric determination of metal ions [6-13]. Several instruments method are present in the literature used to determine copper ion, and these method inductively coupled plasma atomic emissions spectrometry [14,15], flame and electro thermal atomic absorption spectrometry [16,17], flow injection [18-19].According to the best of our knowledge , this reagent has not been reported in the literature as being used for any cation determination. In this study, we wish to report the electrochemical behavior of this reagent and as a selective reagent in spectrophotometric determination of micro amounts of copper (II).BTHN is a tridentate via azo group, hydroxyl group and nitrogen atom of thaizol group : it has the following structure:

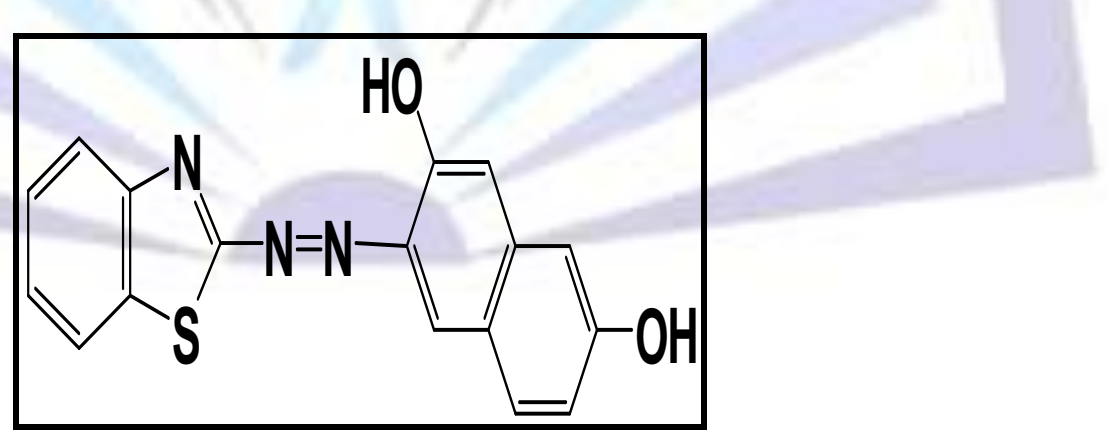

Structure of the (BTHN)

Experimental: All chemicals used in this work were of analytical grade.

In this study the FT-IR spectra of azo compound was recorded on Schimadzu FT-IR spectrophotometer model in $\mathrm{KBr}$ wafer and the NMR spectra was obtained on BRUKER AV 400 Avancelll 400MHz instrument using DMSO as solvent and reported relative to TMS as internal standard, CE440CHN/O/S Elemental Analyser was made by EAI while voltammetric experimentas were carried out using a computer - controlled electroanalysis system using an( EZ-State by NuVant) system .A three- electrod compination system was an $\mathrm{Ag} / \mathrm{AgCl}$ reference electrode, a Pt wire auxiliary electrode and glassy carbone electrode as working electrode, the potential range selected was in the Range(1-1.25) mV. All measurements were carried out at room temperature. 


\section{Synthesis of thaizol derivative :}

2- amino Benzothaizole $(0.0066 \mathrm{~mole}) 1.0000 \mathrm{~g}$ was diazotized by dissolving it in $(5 \mathrm{ml})$ ethanol then $(15 \mathrm{ml})$ of $\mathrm{HCl}(4 \mathrm{M})$ was added keeping the temperature at (0-5Cㅇ) then adding $\mathrm{NaNO}_{2}$ solution gradually and left it about (15min) to cool well. The coupling material (2,7-dihydroxy naphthalen) $(0.0066$ mole) $(1.0650 \mathrm{~g})$ was dissolved in $15 \mathrm{ml}$ of $\mathrm{NaOH}(4 \mathrm{M})$ and leave to cool well , then this solution was added to diazonium salt solution slowly drop by drop to maintain temperature (0-5Cㅇ)The mixture was allowed precipitate was filtered off and washed several times with (1:1) (alcohol:water) mixture then recrystallized from boiling ethanol and left to dry. Scheme (1).Dark Burgundy powder,m.p 230C - Anal(calc) for

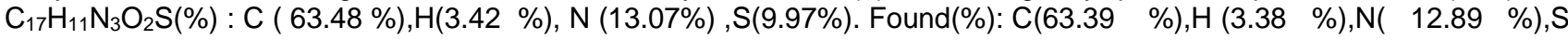

(9.82\%).
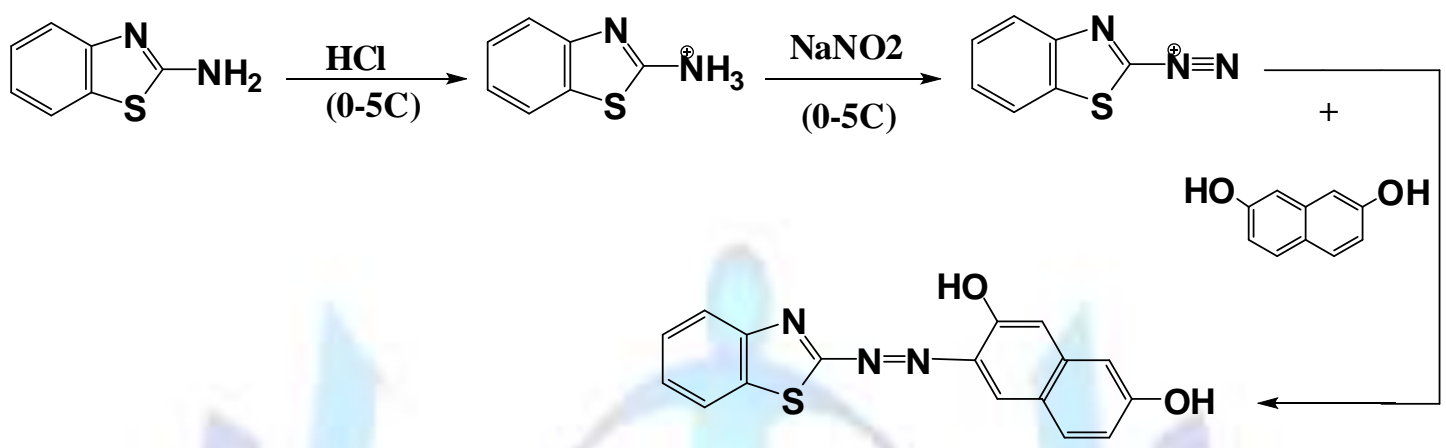

\section{scheme (1).Synthesis of reagent (BTHN)}

\section{Reagents}

Copper stock solution ( 100

chloride in $(200 \mathrm{ml})$ of deionized water.

3(benzothiazol-2-diazenyl naphthalen-2,7diol(1X10 $\left.{ }^{-3} \mathrm{M}\right)$ :This solution was prepared by using ( $0.0321 \mathrm{~g})$ of reagent in $(100 \mathrm{ml})$ of eathanol.

Other ions (foreign) solution: All of ions were prepared by using a suitable amount of the compound in deionized water in a calibrated flask.

\section{Results and Discussion:}

\section{Absorption Spectra:}

The reagent (BTHN) )nm possess a maximum absorption at $440 \mathrm{~nm}$ (Fig .1) reacts with $\left(\mathrm{CuCl}_{2} .2 \mathrm{H}_{2} \mathrm{O}\right)$ at $\mathrm{room}$ temperature to give a (BTHN-Cu(II) colored complex at $\mathrm{pH} 7$. . The absorption spectrum shows a maximum at $588 \mathrm{~nm}$ whereas the reagent blank give no absorption at this wavelength ( Figure. 2)

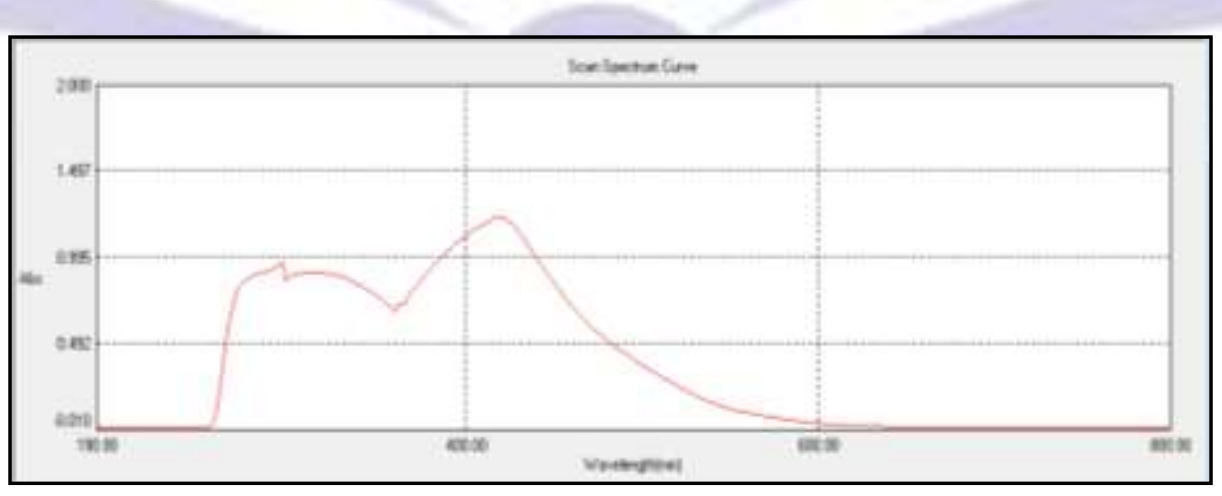

Fig (1)Absorption spectrum of reagent (BTHN) 


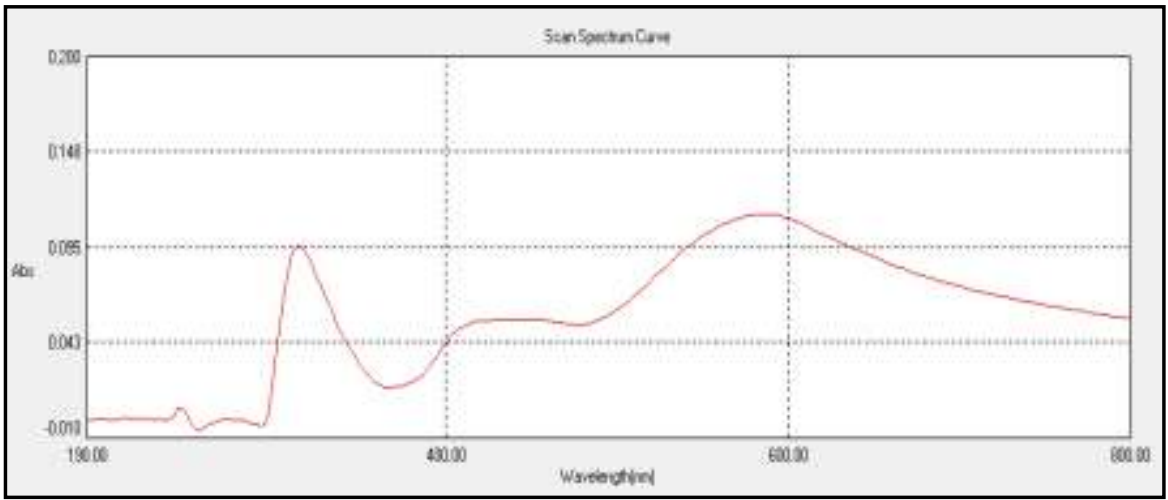

Fig(2)Absorption spectrum of (BTHN-Cu(II))

The effect of various parameters on the absorption intensity of the formed products was

studied and the reactions condition were optimized. The reaction of(BTHN) with $\mathrm{Cu}(\mathrm{II})$ was studied at different $\mathrm{pH}$ by using $\mathrm{HCl}$ or $\mathrm{NaOH}(0.05 \mathrm{~N})$ in the range $(2-10)$. It was found that the chelating complex was formed at $\mathrm{pH}$. (Fig. 3) . It was found that absorbance rises with increasing reagent concentration and got its maximum value on using $\left(1.5 \mathrm{ml}\right.$ of $1 \times 10^{-3}$ $\mathrm{M}$ ) in supsequent experiment.

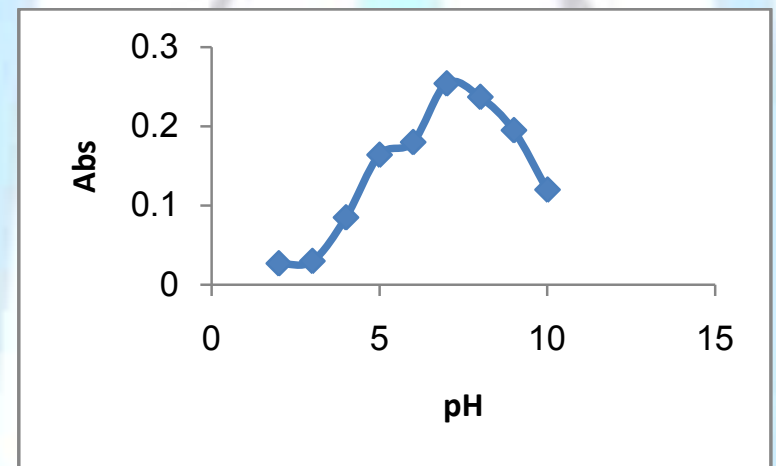

Fig (3) Effect of pH on the color intensity of (BTHN-Cu(II) complex

\section{Quantification:}

In order to study the range in which the colored complex adhere to Beer's law the absorbance of the complex was measured at $\lambda$ max for sequence of solutions containing increasing amounts of $\mathrm{Cu}$ (II) at optimum conditions. The validity of Beers law , molar absorptivity and Sandells sensitivity values were estimated and are given in Table .1, showed that the method is sensitive. The proposed method showed a good linearity for the determination of $\mathrm{Cu}$ (II) with a good correlation coefficient $(0.9588)$. The relative standard devaiation \%(RSD) for the analysis of six replicates of $\mathrm{Cu}(\mathrm{II})$ is equal to(0.464)showed that the method is precise and accurate, while detection limit is equal to $(0.0139)$. The stiochiometric ratio of $(B T H N)$ and $\mathrm{Cu}(\mathrm{II})$ was studied applying the continuous variation(Job's) and mole ratio methods [20,21] using equimolar solutions of the new ligand and $\mathrm{Cu}(\mathrm{II})\left(1^{*} 10^{-4}\right)$.It was found that (BTHN) forms a dye coupled product with $\mathrm{Cu}(\mathrm{II})$ in the ratio 2:1 as in (Figure. 4).

\section{Table (1) characteristics data of $\mathrm{Cu}(\mathrm{II})-\mathrm{BTHN}$ complex}

\begin{tabular}{|l|c|}
\hline \multicolumn{1}{|c|}{ parameter } & Values of method \\
\hline Beers law limits $\left(\mu \mathrm{g} . \mathrm{ml}^{-1}\right)$ & $(0.1-3.0)$ \\
\hline Molar absorptivity $\left(\mathrm{L.mol}^{-1} . \mathrm{cm}^{-1}\right)$ & $1.436 * 104$ \\
\hline LOD $(\mu \mathrm{g} / \mathrm{ml})$ & 0.0139 \\
\hline R.S.D \% & $0.464 \%$ \\
\hline Correlation coefficient & 0.9588 \\
\hline Sandell's sensitivity $\mu \mathrm{g} \mathrm{. \textrm {cm } ^ { - 2 }}$ & 0.0044 \\
\hline
\end{tabular}




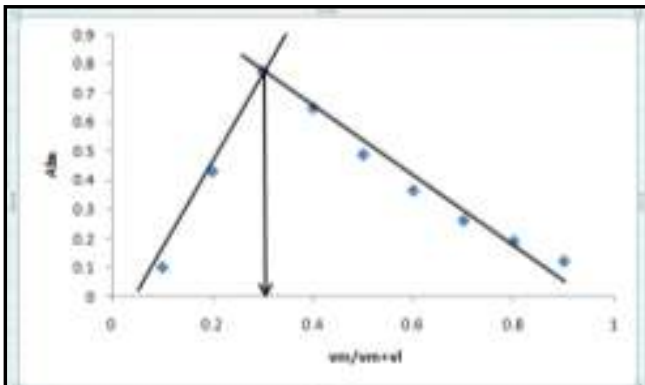

Fig( 4 )continuous variation plot of the Cu-BTHN

\section{F TI.R Analysis:}

The FT-IR spectra of the free ligand have abroad band about(3421-3176) $\mathrm{cm}^{-1}$ which could be attributed to(-OH)stretching vibration ,the shape and intensity of band were changed that led to expect coordination wasaccurein complex(Cu-BTHN), likewise the stretching frequency of $(\mathrm{N}=\mathrm{N})$ at $(1561) \mathrm{cm}^{-1}$ was shifted to a lower frequency $(1531) \mathrm{cm}^{-1}$ in complexes. The bands at frequency $(1651-1593)$ of $(\mathrm{C}=\mathrm{N})$ also was changed as well as the band at(1305-1201) which corresponding with $(\mathrm{C}-\mathrm{N}=\mathrm{N}-\mathrm{C})$ and $(\mathrm{C}=\mathrm{N}-\mathrm{N}=\mathrm{C})$ were shifted towards lower frequency[22-24]. The FT-IR spectra of copper complex also shows additional bands in (495) $\mathrm{cm}^{-1}$ which is due to the formation of (M-O) and (449) $\mathrm{cm}^{-1}$ for (M-N). (Fig. 5.6)

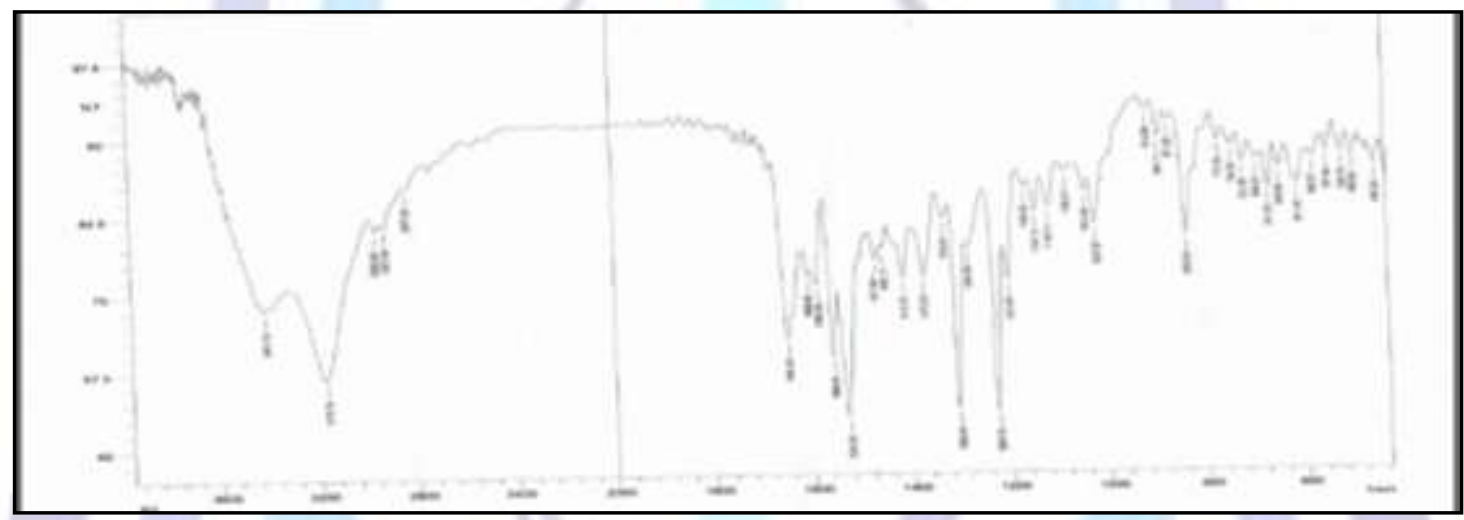

Fig (5) TheFT- IR Spectrum of the dye (BTHN)

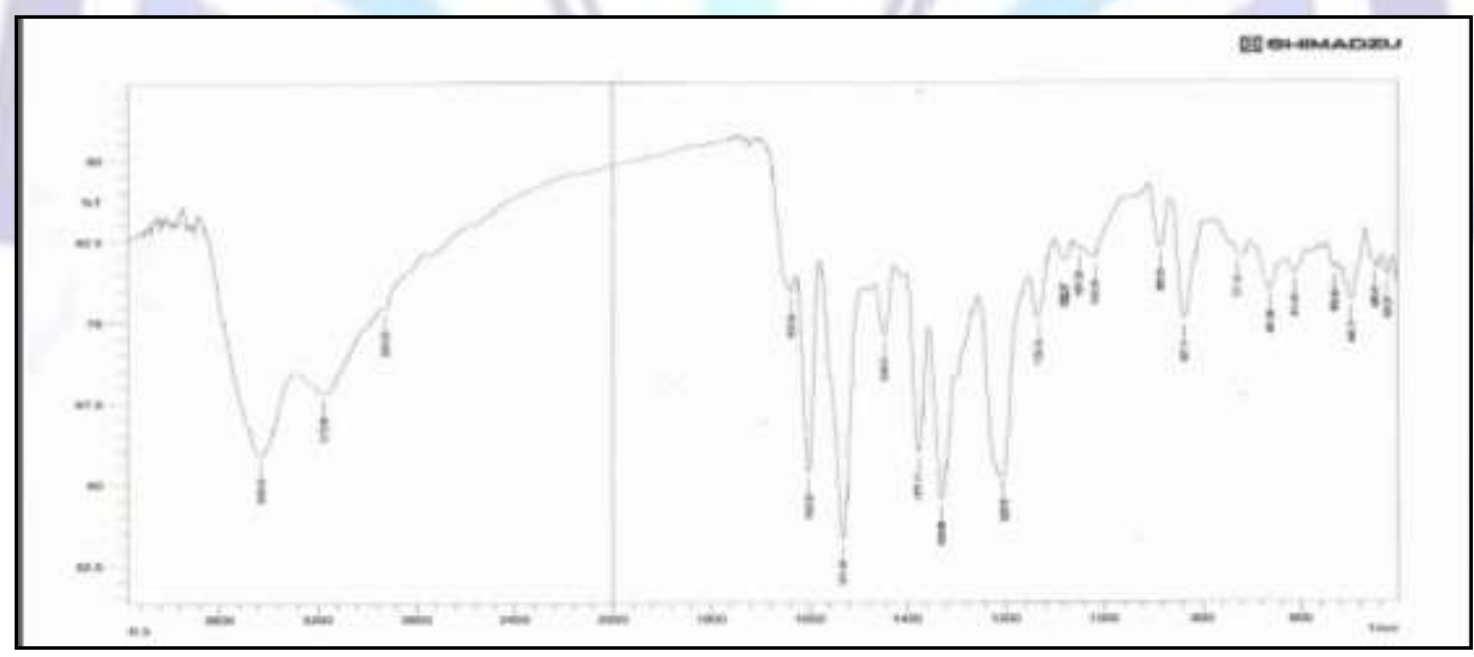

Fig(6)The FT-IR Spectrum of (Cu-BTHN)complex

\section{${ }^{1}$ H-NMR data of BTHN and it complex with Copper(II) :}

The ${ }^{1} \mathrm{H}-\mathrm{NMR}$ and ${ }^{13} \mathrm{C}-\mathrm{NMR}$ spectra of the prepared azocompound was made ligand in DMSO solution with tetra methylsaline as an internal standard indications the following signals as in Table. 2 and Table .3.( Fig.7-10) 
Table(2 ) ${ }^{1}$ H-NMR data of BTHN and it complex with Copper(II)

\begin{tabular}{|l|l|l|l|l|l|}
\hline compound & C-OHAr & $\mathrm{CH}-$ & $\begin{array}{l}\text { Ar-H } \\
\text { naphthalene }\end{array}$ & $\begin{array}{l}\text { CH } \\
\text { benzothaizol }\end{array}$ & $\begin{array}{l}\text { CH3 of } \\
\text { DMSO }\end{array}$ \\
\hline BTHN & $\begin{array}{l}10.3 \\
8.48\end{array}$ & ---- & $6.93-6.184$ & 7.84 & 2.5 \\
\hline Cu-BTHN & 10.2 & 3.387 & $7.120-6.8$ & $7.32-7.75$ & 2.5 \\
\hline
\end{tabular}

Table (3) ${ }^{13}$ C-NMR data of BTHN and Cu-BTHN complex

\begin{tabular}{|c|c|c|c|c|c|}
\hline compound & $\begin{array}{c}C-N \\
\text { benzothaizol }\end{array}$ & $\begin{array}{c}\mathrm{C}-\mathrm{OH} \\
\text { naphthalene }\end{array}$ & $\begin{array}{c}C-H \\
\text { benzothaizol }\end{array}$ & $\begin{array}{c}C-H \\
\text { napthalene }\end{array}$ & $\begin{array}{c}C-N \\
\text { naphthalene }\end{array}$ \\
\hline $\begin{array}{c}\text { BTHN and } \\
C u-B T H N\end{array}$ & 160 & 156.3 & 136.76-122.34 & 122.34-115.7 & 107.7 \\
\hline & $\therefore \quad * \quad *$ & 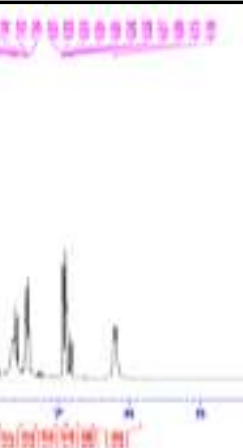 & 945 & 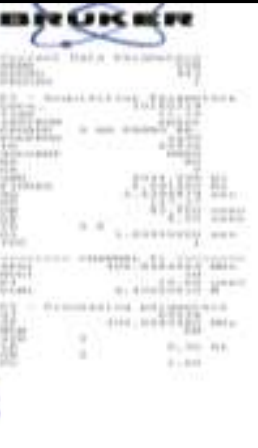 & \\
\hline
\end{tabular}

Fig ( 7):The ${ }^{1} \mathrm{H}$ NMRspectrum of azo compound (BTHN)

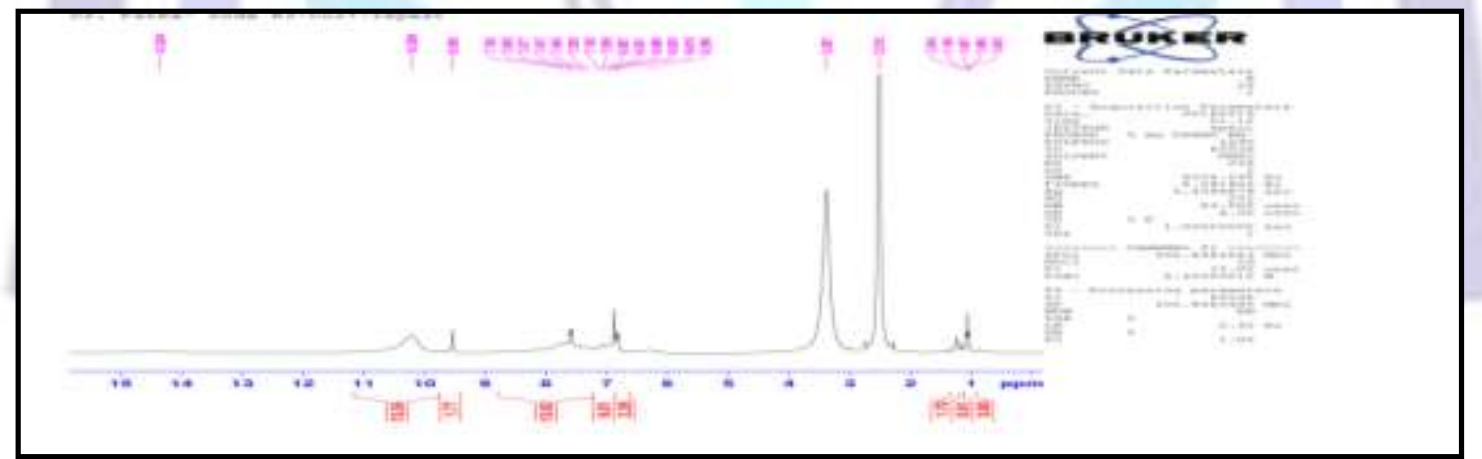

Fig ( 8 ): The ${ }^{1}$ H NMRspectrum of(Cu-BTHN)complex 


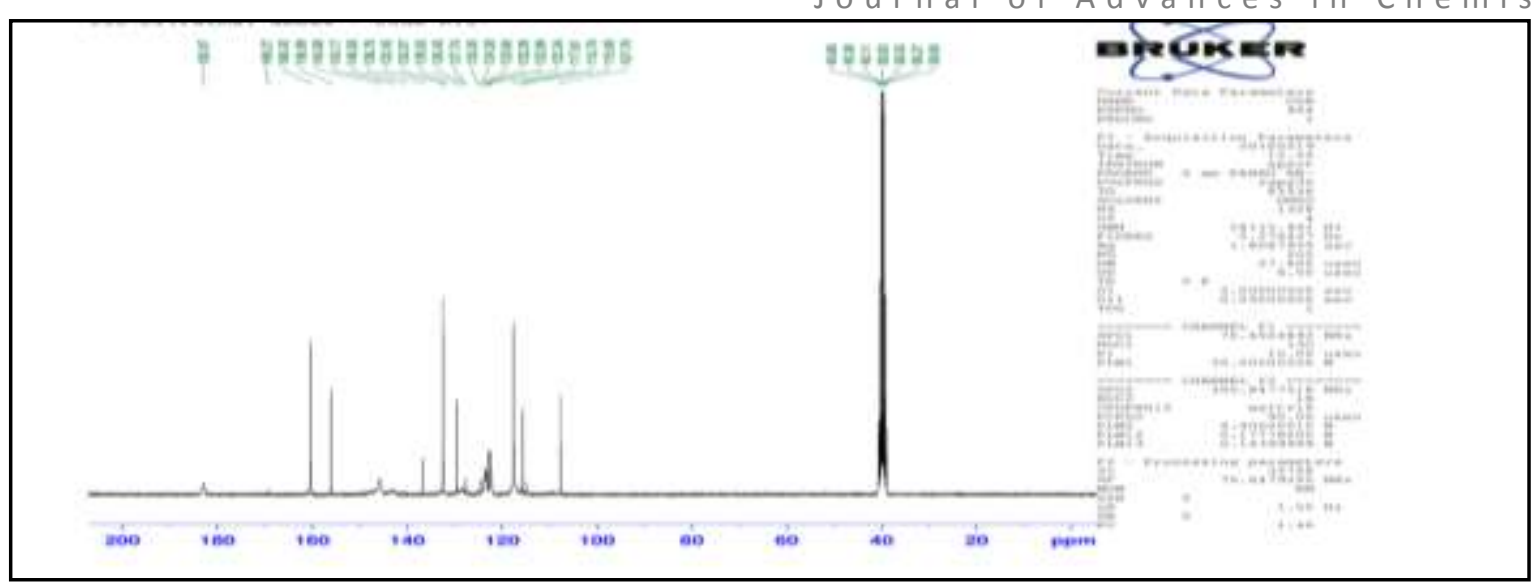

Fig ( 9 ): The ${ }^{13} \mathrm{C}$ NMR spectrum of compound (BTHN)

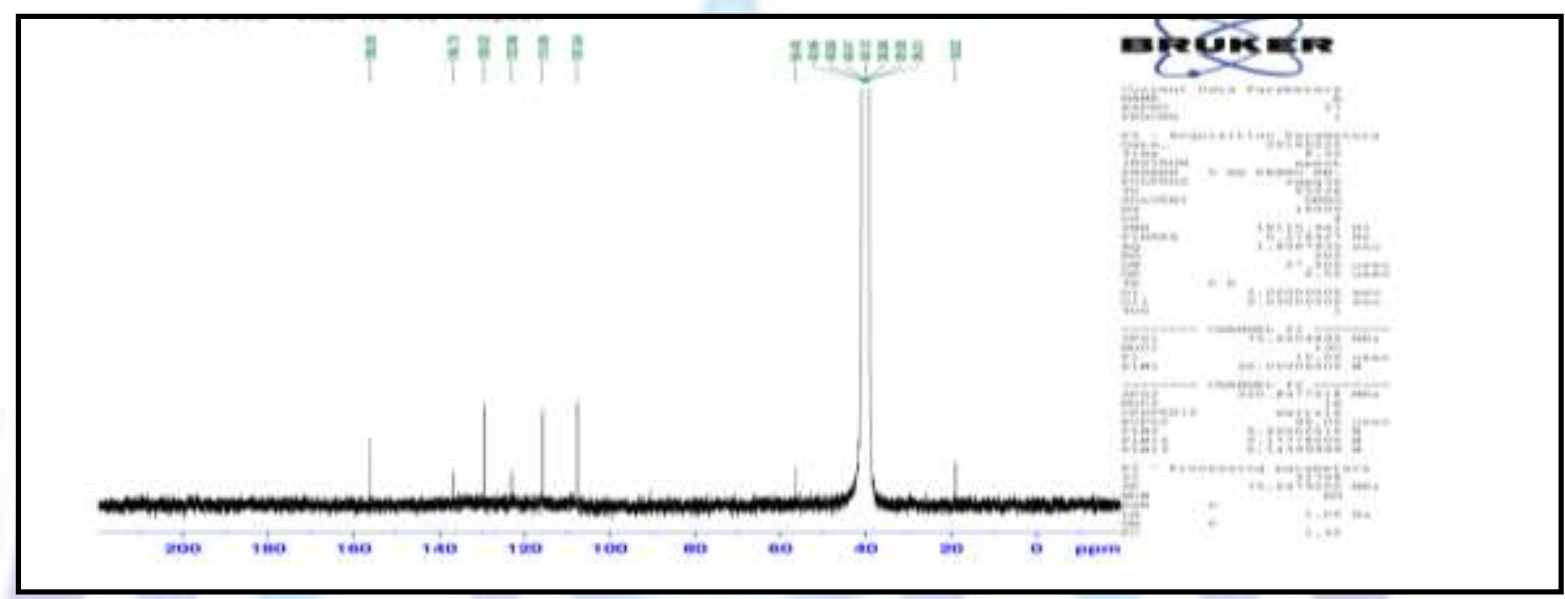

Figure ( 10$)$ :The ${ }^{13} \mathrm{C}$ NMR spectrum of complexCu-(BTHN)

According to the results of the FT-IR, ${ }^{1} \mathrm{H}-\mathrm{NMR}{ }^{13} \mathrm{C}-\mathrm{NMR}$, stoichiometric and elemental analysis the structure of complex can be suggested as the following:

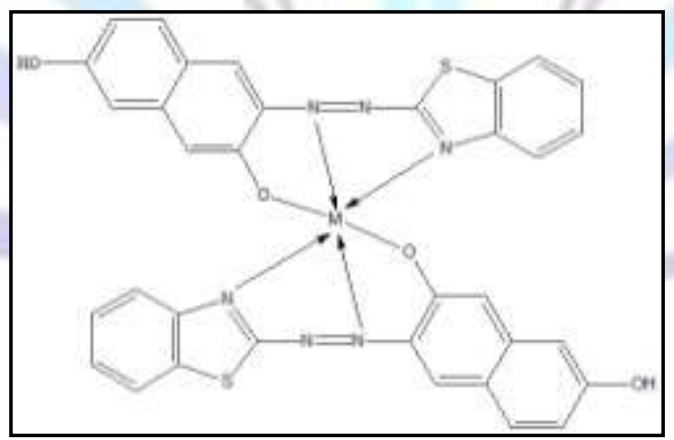

Structure of (BTHN)

\section{Interferences}

The effect of different ions in the determination of copper (II)was studied. Cu(II) can be determined in presence of 10 or more fold excess of cation and the interference via the various ions were removed by using suitable masking agent Table(4) 
Table( 4 ):Interferenc of ions and removed them by masking agent

\begin{tabular}{|c||c|c|c|c|c||}
\hline No & $\begin{array}{c}\text { Foreign } \\
\text { ions }\end{array}$ & $\begin{array}{c}\text { Conc. } \\
\mathrm{ppm}\end{array}$ & Error\% & $\begin{array}{c}\text { Masking } \\
\text { agent }\end{array}$ & Error\% \\
\hline \hline 1 & $\mathrm{Co}^{+2}$ & 10 & 48.08 & Thiourea(1ml) & 0.52 \\
\hline \hline 2 & $\mathrm{Cd}^{+2}$ & 10 & 1.21 & ---- & ---- \\
\hline \hline 3 & $\mathrm{Sr}^{+2}$ & 10 & -3.11 & ---- & ---- \\
\hline \hline 4 & $\mathrm{Ni}^{+2}$ & 10 & -35.88 & Formaldehyde $(0.5 \mathrm{ml})$ & 0.36 \\
\hline \hline 5 & $\mathrm{Sn}^{+2}$ & 10 & 2.7 & ---- & ---- \\
\hline \hline 6 & $\mathrm{Cs}^{+2}$ & 10 & 1.52 & ---- & ---- \\
\hline \hline 7 & $\mathrm{Zn}^{+2}$ & 10 & 0.8 & ---- & ---- \\
\hline \hline 8 & $\mathrm{~Pb}^{+2}$ & 10 & -2.39 & ---- & ---- \\
\hline \hline 9 & $\mathrm{Mn}^{+2}$ & 10 & 12 & Formaldehyde $(1 \mathrm{ml})$ & 0.28 \\
\hline \hline 10 & $\mathrm{Hg}^{+2}$ & 10 & -1.913 & ---- & ---- \\
\hline \hline 11 & $\mathrm{Ag}^{+1}$ & 10 & 2.8 & ---- & ---- \\
\hline \hline 12 & $\mathrm{Fe}^{+3}$ & 10 & 51.3 & $\mathrm{Na}_{2} \mathrm{HPO}_{4}(1 \mathrm{ml})$ & 0.45 \\
\hline
\end{tabular}

\section{Determination of Copper(II) in honeysample}

$0.1 \mathrm{~g}$ of honey digested in microwave with $5 \mathrm{ml}$ of concentrated $\mathrm{HNO}_{3}$ and $3 \mathrm{ml}$ of $30 \% \mathrm{H}_{2} \mathrm{O}_{2}$. The result of digested solution was diluted to $100 \mathrm{ml}$ with deionized water , from this solution transfer $2 \mathrm{ml}$ in centerfuge tube for $10 \mathrm{~min}$ and analysis with UV-Vis proposed method and atomic absorption [25] . The results are shown in Table 5, indicate that satisfactory precision and accuracy could be attained with proposed method

\section{Table( 5 ):Cu(II) levels in Honey Sample}

\begin{tabular}{|c|l|l|}
\hline Tabe of Honey & $\begin{array}{l}\text { Amount found by our } \\
\text { spectrophotometric } \\
\text { method }\left(\mu \mathrm{g} . \mathrm{m}^{-1}\right)\end{array}$ & $\begin{array}{l}\text { Amount found by Atomic } \\
\text { Absorbtion }\left(\mu \mathrm{g} . \mathrm{mr}^{-1}\right)\end{array}$ \\
\hline $\begin{array}{c}\text { Granja San } \\
\text { Francisco }\end{array}$ & 0.33 & 0.29 \\
\hline
\end{tabular}

\section{Electrochemical behavior of azo dye(BTHN)and redox mechanisum in aqueous}

\section{solution:}

The cyclic voltammogrames of investigated azo dyes shown one to three irreversible cathodic peaks [26 ,27] .The number of peaks depends on $\mathrm{pH}$ and nature of compounds. The peaks observed are due to the reduction of azo $-\mathrm{N}=\mathrm{N}$ - center. The reduction mechanism includes the formation of hydrazo derivatives followed by the cleavage of the $-\mathrm{N}=\mathrm{N}$ - bond and the final formation of amines $[28,29]$ according to the following

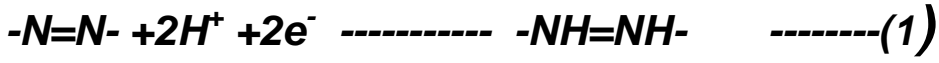

$$
\begin{aligned}
& -\mathrm{NH}=\mathrm{NH}-+2 \mathrm{H}^{+}+2 \mathrm{e}^{-} \quad---\cdot-----2\left(-\mathrm{NH}_{2}-\right)
\end{aligned}
$$


Different supporting electrolyte was be used with the reagent(BTHN) at GCE with scan rate $\left(0.1 \mathrm{Vs}^{-1}\right)$ for all cyclic voltammogrames. All voltammogrames are shows reduction peak of azo group (-N=N-) at potential ranged $(-500 \mathrm{mv}-750 \mathrm{mv})$. The choice of the better supporting electrolyte depends on the higher current for oxidation peak and clarity of peak (Fig.12-14) Table .6 .

For reagent(BTHN) was proposed that the best supporting electrolyte is $(\mathrm{KCl})$ (Fig. 11,12),current was highest between other electrolytes, cyclic voltammogram shows irreversible electrochemical system in which the electron transfer rates are significantly less than the rate of mass transport and the reduction in two steps , the first reduction attributed to azo group giving a hydrazo derivative, second reduction peak to breaks $\mathrm{N}-\mathrm{N}$ linkage to form two primary amine molecules (scheme . 2). All current peak ratio shows irreversibility of electrochemical system at different electrolyte due to the Ipc/lpa $\neq 1$ Table .7, the deviation from number one due to the chemical reaction that arises subsequent transmission electron ,such interactions can be complex , involving dissociation and isomerization [30].

Table(6) Current -Potential data of(BTHN) in several supporting electrolyte Solution $(1 \mathrm{M})$ with scan rate $\left(0.1 \mathrm{Vs}^{-1}\right)$

\begin{tabular}{|c|c|c|c|c|c|c|c|c|c|c|c|c|c|}
\hline R3 & $\begin{array}{l}\text { Supporting } \\
\text { Electrolyte }\end{array}$ & $\begin{array}{l}\mathrm{I}_{1} \\
\mu \mathrm{A}\end{array}$ & $\begin{array}{l}\mathrm{Ea}_{1} \\
\mathrm{mv}\end{array}$ & $\begin{array}{l}\mathrm{Ia}_{2} \\
\mu \mathrm{A}\end{array}$ & $\begin{array}{l}-E a_{2} \\
m v\end{array}$ & $\mathrm{Ia}_{3} \mu \mathrm{A}$ & $\begin{array}{l}-\mathrm{Ea}_{3} \\
\mathrm{mv}\end{array}$ & $\begin{array}{l}-\mathrm{Ic}_{1} \\
\mu \mathrm{A}\end{array}$ & $\begin{array}{l}-E c_{1} \\
m v\end{array}$ & $\begin{array}{l}\mathrm{IC}_{2} \\
\mu \mathrm{A}\end{array}$ & $\begin{array}{l}-\mathrm{Ec}_{2} \\
\mathrm{mv}\end{array}$ & $\begin{array}{l}\mathrm{IC}_{3} \\
\mu \mathrm{A}\end{array}$ & $\begin{array}{l}\mathrm{Ec}_{3} \\
\mathrm{mv}\end{array}$ \\
\hline 1 & $\mathrm{KCl}$ & 14.5 & 461 & 5.38 & 246 & --- & --- & 22.6 & 510 & 27.3 & 701 & & \\
\hline 2 & $\mathrm{KClO3}$ & 5.31 & -250 & $11.8-$ & 679 & --- & --- & 23.0 & 497 & --- & --- & & \\
\hline 3 & K2HPO4 & 7.95 & 266 & 3.64 & 113 & -- & --- & 21.4 & 701 & -- & --- & & \\
\hline 4 & KNO3 & 7.50 & 66.5 & 3.41 & 276 & -- & --- & 6.59 & 159 & 24.1 & 688 & & \\
\hline 5 & K2SO4 & 8.41 & 465 & 5.45 & 220 & -6.59 & 677 & 5.68 & 192 & 23.9 & 599 & & \\
\hline 6 & $\mathrm{NaCl}$ & 9.76 & 497 & 6.19 & 132 & 3.88 & 335 & 5.77 & 146 & 21.3 & 580 & & \\
\hline 7 & $\mathrm{NaH} 2 \mathrm{PO} 4$ & 9.62 & 699 & 6.15 & 89.6 & --- & -- & 5.19 & 163 & 23.5 & 675 & & \\
\hline 8 & $\mathrm{Na2HPO4}$ & 9.72 & 78.9 & -- & --- & --- & -- & 23.1 & 596 & -- & -- & & \\
\hline 9 & TBABr & No res. & & & & & & & & 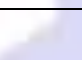 & & & \\
\hline 10 & B.R & No res. & & & & & & & & & & & \\
\hline
\end{tabular}

Enhancement in current of peak follows the following sequence:

$\mathrm{KCl}>\mathrm{NaCL}>\mathrm{Na}_{2} \mathrm{HPO}_{4}>\mathrm{NaH}_{2} \mathrm{PO}_{4}>\mathrm{K}_{2} \mathrm{SO}_{4} \mathrm{~K}_{2} \mathrm{HPO}_{4}>\mathrm{KNO}_{3}>\mathrm{KClO}{ }_{3}$

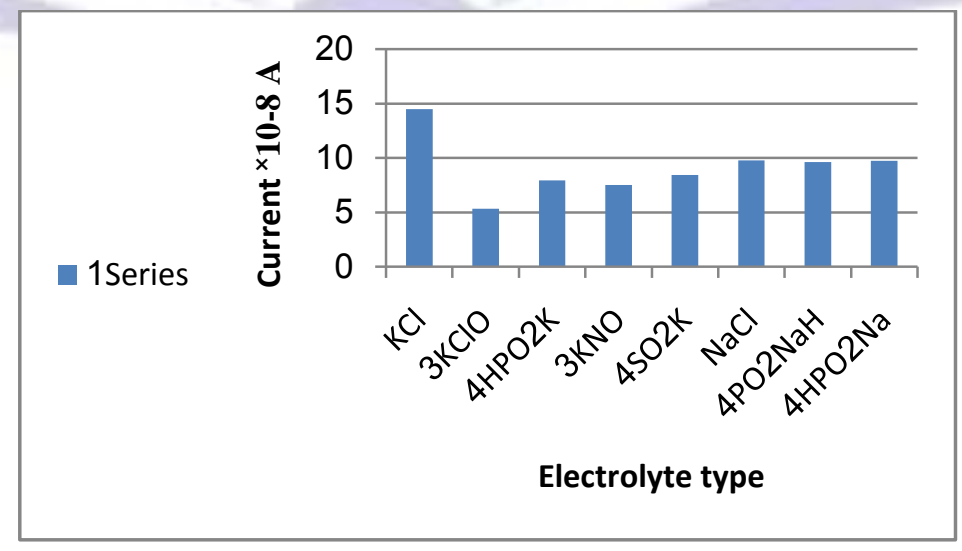

Fig(11) Effects of supporting electrolyte on the anodic peak current of reagent (BTHN) 
Table ( 7 )Current -Potential data for(BTHN)) at different supporting electrolyte (1M) and scan rate ( $0.1 \mathrm{Vs}-1)$

\begin{tabular}{|c|l|c|c|c|c|c|c|c|}
\hline & $\begin{array}{l}\text { Supporting } \\
\text { electrolyte }\end{array}$ & $\begin{array}{c}E a_{1} \\
m V\end{array}$ & $\begin{array}{c}-E c_{1} \\
m V\end{array}$ & $\begin{array}{c}l a_{1} \\
\mu A\end{array}$ & $\begin{array}{c}-I c_{1} \\
\mu A\end{array}$ & $\Delta E_{1} m V$ & $E_{1 / 2}$ & $I a_{1} / l_{1}$ \\
\hline 1 & $\mathrm{KCl}$ & 461 & 14.5 & 510 & 22.6 & 49 & -24.5 & 0.641 \\
\hline 2 & $\mathrm{KClO}_{3}$ & -250 & 497 & 5.31 & 23.0 & 248 & 373.5 & 0.230 \\
\hline 3 & $\mathrm{KNO}_{3}$ & 66.5 & 159 & 7.50 & 6.59 & 225.5 & -46.25 & 1.138 \\
\hline 4 & $\mathrm{~K}_{2} \mathrm{HPO}_{4}$ & 266 & 701 & 7.95 & 21.4 & 435 & -217.5 & 0.371 \\
\hline 5 & $\mathrm{NaCl}$ & 497 & 146 & 9.76 & 5.77 & 643 & 175.5 & 1.691 \\
\hline 6 & $\mathrm{Na}_{2} \mathrm{HPO}_{4}$ & 78.9 & 596 & 596 & 23.1 & 674.9 & -258.55 & 0.420 \\
\hline 7 & $\mathrm{NaH}_{2} \mathrm{PO}_{4}$ & 699 & 163 & 9.62 & 5.19 & 862 & 268 & 1.85 \\
\hline
\end{tabular}

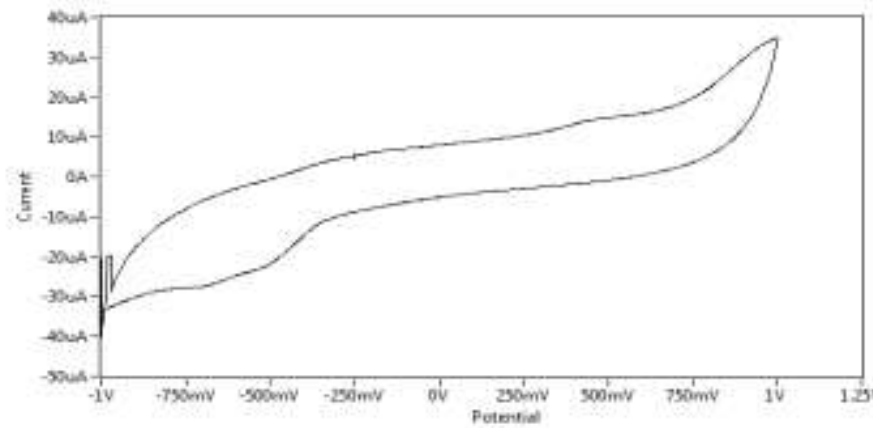

Fig (12) Cyclic voltammogramof (BTHN) in supporting electrolyte $1 \mathrm{M}$ of $\mathrm{KCl}$ at scan rate $0.1 \mathrm{Vs}^{-1}$

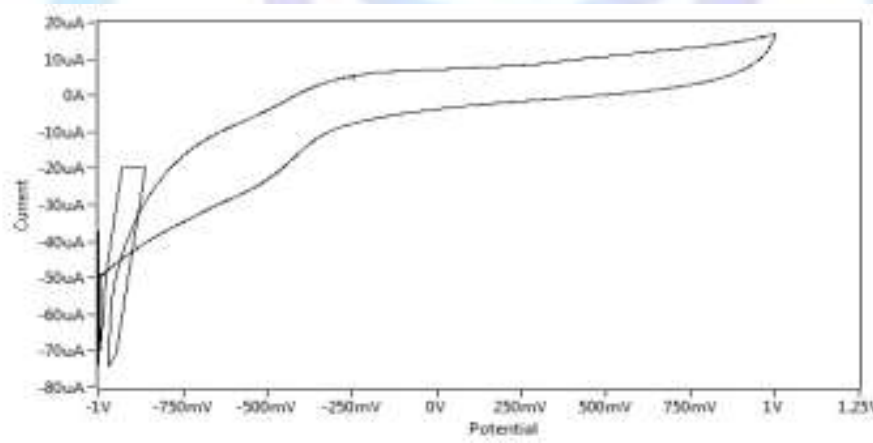

currem $ه$

Fig (13) Cyclic voltammogram of(BTHN)in supporting electrolyte $1 \mathrm{M}$ of $\mathrm{KClO}_{3}$ at scan rate $0.1 \mathrm{Vs}^{-1}$

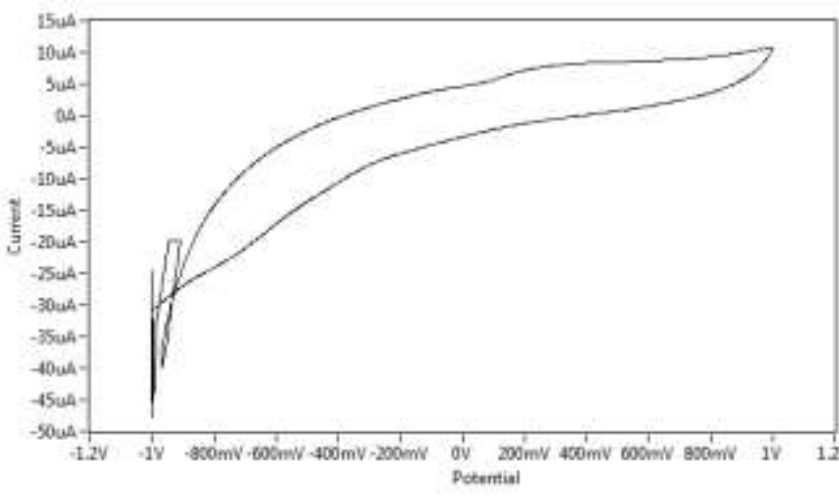


Fig (14) Cyclic voltammogram of (BTHN) in supporting electrolyte $1 \mathrm{M}$ of $\mathrm{K}_{2} \mathrm{HPO}_{4}$ at scan rate $0.1 \mathrm{Vs}-1$<smiles>Oc1ccc2cc(N=Nc3nc4ccccc4s3)c(O)cc2c1</smiles>

\section{Scheme(2 ) Proposed mechanism of voltammetric reduction of reagent(BTHN)}

\section{Redox behavior of(Cu-BTHN) complex}

Cyclic voltammograms of copper complex was recorded in different supporting electrolyte ,the results are summarized in Table.8 (Fig. 15-18), $\mathrm{NaH}_{2} \mathrm{PO}_{4} 1 \mathrm{M}$ as supporting electrolyte was proposed the best electrolyte depending on the clarity of redox peaks (Fig . 23). It clearly reveals that the redox process of the copper (II) complex at the scane rate $\left(0.1 \mathrm{Vs}^{-1}\right)$ involves one reduction cathodic peak $(\mathrm{Epc}=-48.6 \mathrm{mv})$. In the anodic side the direct oxidation of complex is observed with a strong peak at $\mathrm{Epa}=90.2 \mathrm{mv}$ ). It is observed that $\Delta \mathrm{Ep}$ values was found equal to $(\mathbf{1 3 8 . 8} \mathrm{mv})$ and the ratio of anodic to cathodic peak currents(Ipa//pc $\neq 1)$ corresponds to more than one electron transfer process. The difference in the value of (Epc-Epa is $\Delta \mathrm{Ep}$ ) which is smaller than the value required for a reversible process ( $59 \mathrm{mv}$ ) indicating that, reduction of copper complex at silver electrode is irreversible Table .9 [31,332].

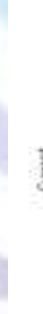

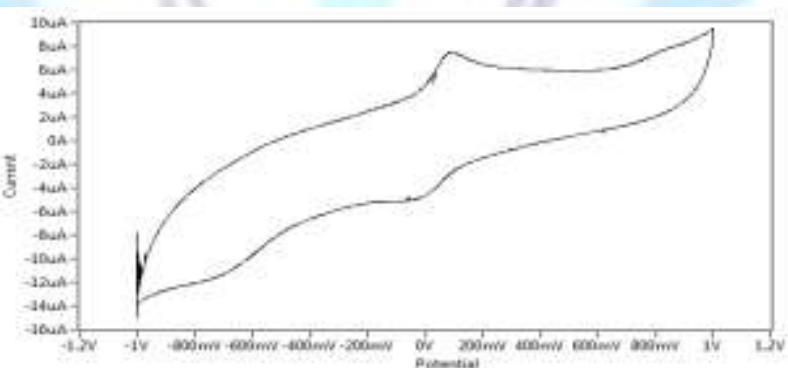

Fig( 15)cyclic voltammograms for( $\mathrm{Cu}-\mathrm{BTHN})$ complex in $\left(\mathrm{NaH}_{2} \mathrm{PO}_{4}\right)(1 \mathrm{M})$ at scan rate $0.1 \mathrm{Vs}^{-1}$

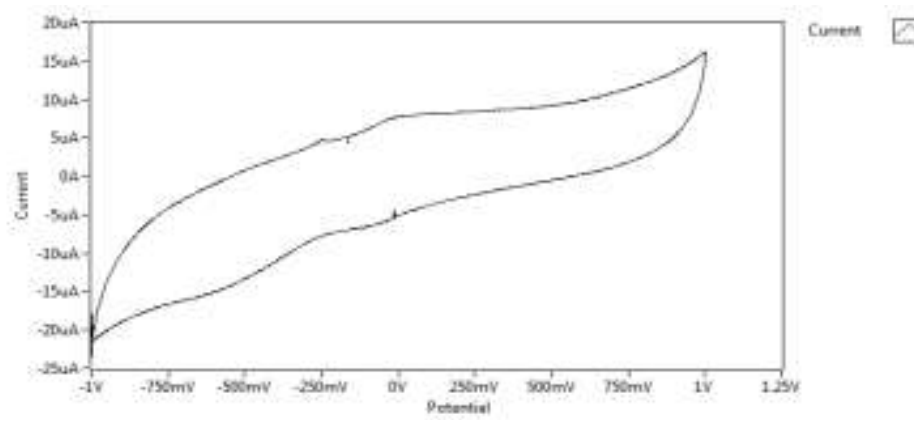


Fig( 16 )cyclic voltammograms for( $\mathrm{Cu}-\mathrm{BTHN})$ complex in $\left(\mathrm{KNO}_{3}\right)(1 \mathrm{M})$ at scan rate $0.1 \mathrm{Vs}^{-1}$

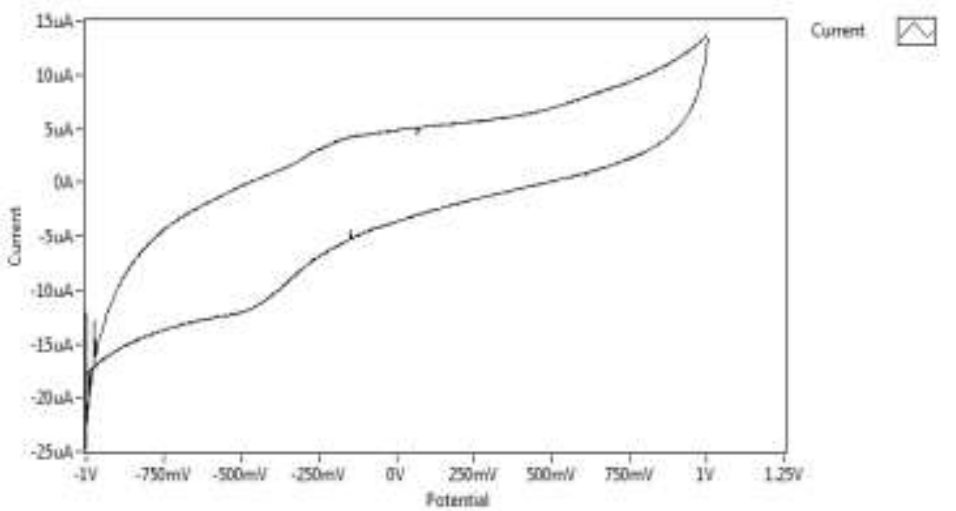

Fig( 17)cyclic voltammograms for( Cu-BTHN)complex in( $\mathrm{NaCl})(1 \mathrm{M})$ at scan rate $0.1 \mathrm{Vs}^{-1}$

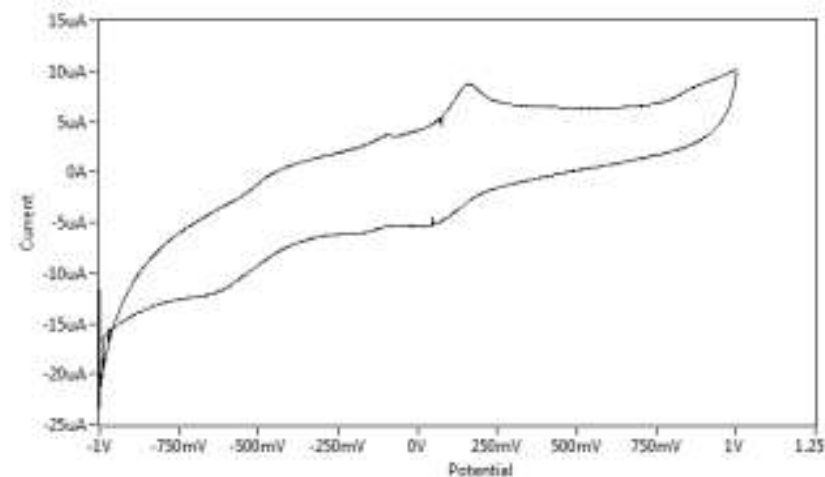

Fig(18)cyclic voltammograms for( Cu-BTHN)complex in $\left(\mathrm{K}_{2} \mathrm{HPO}_{4}\right)(1 \mathrm{M})$ at scan rate $0.1 \mathrm{Vs}^{-1}$

Table ( 8 )Current-Potential data for(Cu-BTHN))complex at different supporting electrolyte $(1 \mathrm{M})$ at scan rate $\left(0.1 \mathrm{Vs}^{-1}\right)$

\begin{tabular}{|c|c|c|c|c|c|c|c|c|c|c|c|c|c|}
\hline & & & & 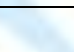 & 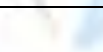 & 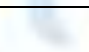 & & & & 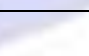 & & & \\
\hline & $\begin{array}{l}\text { Supporting } \\
\text { Electrolyte }\end{array}$ & $\begin{array}{l}I a_{1} \\
\mu A\end{array}$ & $\begin{array}{l}\mathrm{Ea}_{1} \\
\mathrm{mv}\end{array}$ & $\begin{array}{l}\mathrm{Ia}_{2} \\
\mu \mathrm{A}\end{array}$ & $\begin{array}{l}\mathrm{Ea}_{2} \\
\mathrm{mv}\end{array}$ & $\begin{array}{l}l \mathrm{a}_{3} \\
\mu \mathrm{A}\end{array}$ & $\begin{array}{l}E a_{3} \\
\mathrm{mv}\end{array}$ & $\begin{array}{l}-I c_{1} \\
\mu A\end{array}$ & $\begin{array}{l}E c_{1} \\
m v\end{array}$ & $\begin{array}{l}\mathrm{IC}_{2} \\
\mu \mathrm{A}\end{array}$ & $\begin{array}{l}-\mathrm{Ec}_{2} \\
\mathrm{mv}\end{array}$ & $\begin{array}{l}I c_{3} \\
\mu A\end{array}$ & $\begin{array}{l}\mathrm{Ec}_{3} \\
\mathrm{mv}\end{array}$ \\
\hline 1 & $\mathrm{KCl}$ & 9.41 & 626 & 4.37 & 181 & -- & -- & 5.14 & 129 & 12.0 & 471 & -- & -- \\
\hline 2 & $\mathrm{KClO}_{3}$ & 12.2 & 645 & 6.29 & +92.1 & 1.89 & 289 & 29.4 & 535 & -- & -- & -- & -- \\
\hline 3 & $\mathrm{~K}_{2} \mathrm{HPO}_{4}$ & 7.31 & 166 & 3.81 & 80.9 & $\begin{array}{l}385 \\
\text { nA }\end{array}$ & 432 & 4.58 & 53.5 & 6.50 & 211 & 13.0 & 632 \\
\hline 4 & $\mathrm{KNO}_{3}$ & 7.88 & 31.8 & 4.74 & 250 & -- & -- & 6.12 & 59.2 & 14.3 & 549 & -- & -- \\
\hline 5 & $\mathrm{~K}_{2} \mathrm{SO}_{4}$ & 8.08 & 539 & 5.87 & 150 & -- & -- & 5.14 & 133 & 14.7 & 514 & -- & -- \\
\hline 6 & $\mathrm{NaCl}$ & 4.51 & 132 & -- & -- & -- & -- & 11.3 & 460 & -- & -- & -- & -- \\
\hline 7 & $\mathrm{NaH}_{2} \mathrm{PO}_{4}$ & 7.55 & 90.2 & -- & -- & -- & -- & 5.0 & 48.6 & 11.4 & 701 & -- & -- \\
\hline
\end{tabular}


Table ( 9 ) Current -Potential data for(Cu-BTHN)) at $\left(\mathrm{NaH}_{2} \mathrm{PO}_{4}\right)(1 \mathrm{M})$ as supporting electrolyte at scan rate $\left(0.1 \mathrm{Vs}^{-1}\right.$

\begin{tabular}{|l|l|l|l|l|l|l|l|}
\hline compound & $\begin{array}{l}E a_{1} \\
m V\end{array}$ & $\begin{array}{l}E c_{1} \\
m V\end{array}$ & $\begin{array}{l}l a_{1} \\
\mu A\end{array}$ & $-I c_{1} \mu A$ & $\Delta E p$ & $(I p a / I p c)$ & $\begin{array}{l}E_{1 / 2} \\
m V\end{array}$ \\
\hline Cu-BTHN & 90.2 & 48.6 & 7.55 & 5.0 & 138.8 & 1.5 & 20.8 \\
\hline
\end{tabular}

\section{Conclusion:}

This work azo employing 3-((benzothiazol-2-diazenylnaphthalene-2,7-diol(BTHN) was successfully applied for the estimation of copper(II) ion .Due to of the sensitivity ,rapidly and selectivity of the method, its application canbe estimation of this ion in biological sample.

The cyclic voltammetric system of (BTHN) led to the formation of same hydrazine derivative which remains at the electrode surface according to equations :

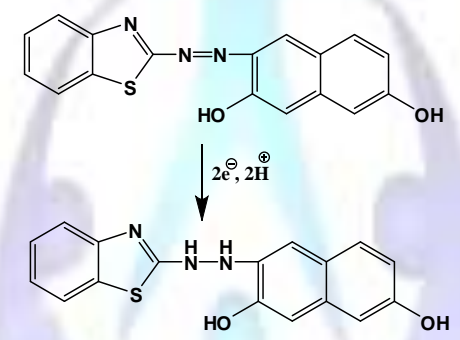

The cyclic voltammetric system of complex (Cu-BTHN) ) led to the formation of two reagent molecule and copper (II) ion according to equation below :

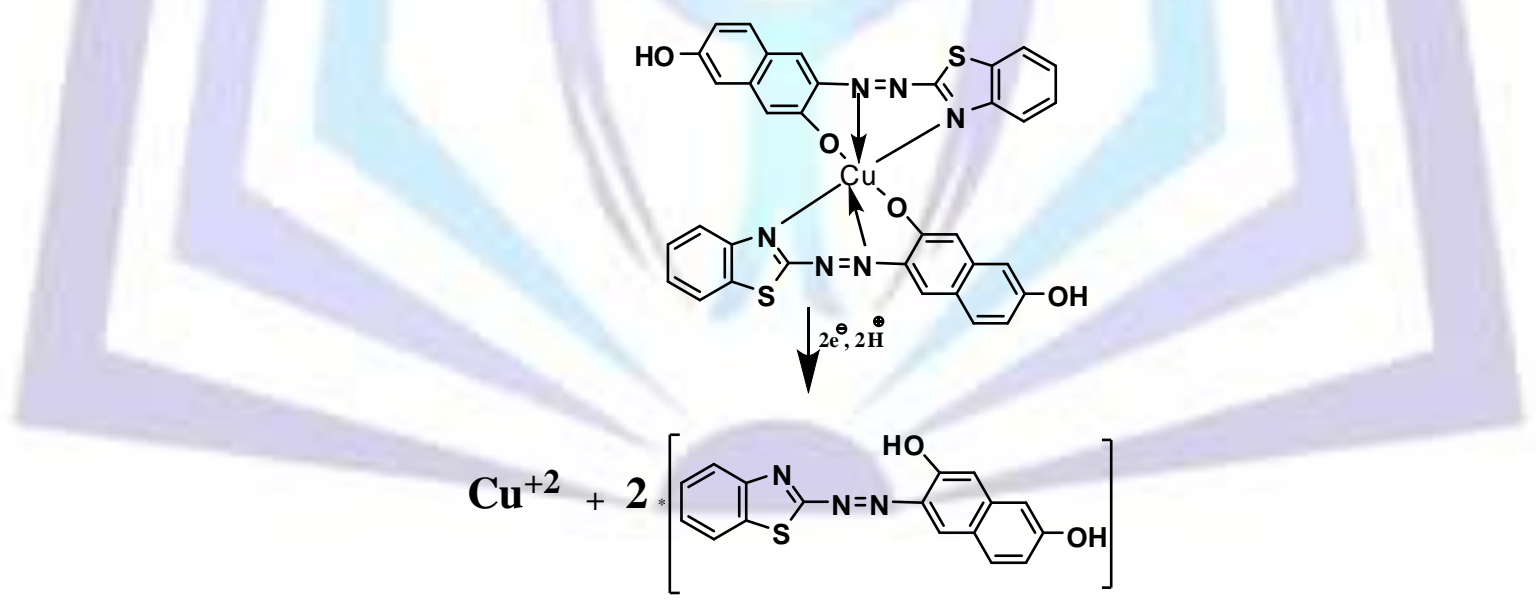

\section{Acknowledgment}

The authors are grateful to the Department of Chemistry, Faculty of Science, University of Kufa to complete the requirements of research

\section{References}

1. 1-D.AJohnson,T.M.Florence,Anal.Chim.Acta,53,73,1971.

2. 2-A.S.Amin,A.S.AL-Attas,J.SaudiChem.Soc.,16,451, 1971.

3. 3-N.Menek,O.Cakir,H.Kocaokutgen,Mikrochim.Acta, 122,203,1996.

4. 4-N.Menek,Ph.D Thesis,, Ondokuz Mayis University,Samsun,Turkey(1994).

5. 5-T.Hihara,Y.Okada and Z.Morita.Dyes and pigments,73,141,2007.

6. 6- H. J Mohammed, A. Y .Muhi and H. al- meisslemaw E-Journal of Chemistry, 8(S1), S425-S433,2011. 
7. 7- H. Khazal and H..J. Mohammed Inter. J. of Civil \& Env Engin IJCEE-IJENS Vol: 14 No: 04,1,2014

8. 8-H.J.Mohammed, M. A.Awad, Sh.H.Mallah, Inter. J. of Basic \& Appl Sci IJBAS-IJENS Vol:15 No:02, 25,2015

9. 9- M.A. Awad and H.J.Mohammed,Chem. Sci. Transactions, 3(3) pp, 2014.

10. 10- N. k. Saeed\&H.J.Mohammed, Inter. J. of Civil \& Env. Eng. IJCEE-IJENS Vol: 14 No: $04,8,2014$.

11. 11-W. Mohammed \& H.J. Mohammed Inter. J. of Civil \& Env. Eng. IJCEE-IJENS Vol:13 No:06 ,37, 2013

12. 12- A.A.Sayhood and H. J. Mohammed, Int. J. Chem. Sci.: 13(3), 1123-113, 2015.

13. 13- A.A.Sayhood and H. J. Mohammed, Der Pharma Chemica,Der Pharma Chemica, 7(8), 50-58, 2015.

14. 14-L.Zhang,Z.Li,X.Du,R.Li and X.Chang,Spectrochimica Acta partA: Molecular and Biomolecular

15. Spectroscopy, $86,443-448,2012$

16. 15-H.Xie,X.D.Nie and Y.G.Tang;Chin.Chem.Lett,17(8),1077-1080,2006.

17. 16-M.Ghaedi,A.Shokrollahi and F.Ahmadi;J.Haz.Mater.,142,272-278,2007

18. 17-S.F.A.Ali,N.Imtiaz,S.U.Mehdi and M.Asif;InternationalConference on Chemical Engineering Pharmaceutical Sciences,(13-15),140-142.2012

19. 18- A. V .Pereira, , \& O.Fatibello-Filho, ;. Anal. Chim. Acta, 366(1), 55-62. (1998).

20. 19-S.Lunvongsa,T.T suboi and S.Motomizu;Anal.Sci.,22,169-172,2006.

21. 20- G. W. Ewing, Instrumental Methods of Chemical Analysis, Mcgraw-Hill College, USA, 5th ed., 1985.

22. 21- W. C. Vosburgh and G. R. Cooper, J. Am. Chem. Soc., 63, 437-442,1941.

23. 22-B.R.Hsieh,D.Desilets, and P.M.Kazmaier, ,'Dyes and Pigments,.14,no.3,.165-189,1990.

24. 23-A.V.Zemskov,G.N.Rodionova,Y.G.Tuchin, and V.V.Karpov,"IR soectra and structure of some azo dyes-pazobenzene derivatives-in various aggregate states,"Zhurnal Prikladnoi Spektroskopii,.49,no.4,.581-586,1988

25. 24-K.Ueno,"Polyazobenzenes.III.Infrared absorption spectra of some polyazobenzenes," J.Am. Chem. Soc,.79,no.12,.3205-3208,1957.

26. 25- Tuzen M, Soylak M , and Elci.L,Anal chim Acta , ,584,101-108,2005.

27. 26-L.Dubenska,H.Levytska, and N.Poperechna,"Polarographic investigation of reduction process of some azo dyes and their complexes with rare -earths" ,Talanta , .54,no 2..221-231,2001.

28. 27- G.W.Latimer, "Polargraphic behavior of metal chelates of o,òdihydroxyazo dyes ," Talanta , .15,no.1,.1-14,1968

29. 28- D.K.Gosser Jr., Cyclic Voltammetry : Simulation and Analysis of reaction Mechanisms ,VCH Publishers ,New York ,NY,USA,1993

30. 29-C.H.Bamford"Electrode kinetic princibles and methodology" .23, .17-21,1986.

31. 30-A.J.Bard and L.R.Faulkner,Electrochemical Methodes ,Fundamentals and Application,Wiley,NewYork.Ny,USA,2nd edition,2001.

32. 31-R.N.Patel,n.Singh, D.K.Patel,and V.L.N.Gundla,"Synthesis,characterization and superoxide dismutase studies of square pyramidal copper (II) complexes with bi and tri dentate polyamine ligands,"Indian Journal of chemistry A.46,no.3,422-427,2007

32- G.D.Levitskaya,N.P.Poperechnaya , and L.O.Dubenskaya, Polarographic behavior of eriochrome red B and its complexes with rare -earth ions,"Journal if Analytical Chemistry , .56,no 6,552-556,2001

4255 | P a g e council for Innovative Research w w w. cirworld.com 